\title{
Effects of orienting instructions on human fixed-interval performance
}

\author{
DUDLEY J. TERRELL, ROBERT H. BENNETT, WILLIAM BUSKIST, and R. ALAN WILLIAMS \\ Auburn University, Auburn, Alabama
}

\begin{abstract}
The effects of orienting instructions-those instructions usually given to human subjects to acquaint them with the experimental task and contextual stimuli prior to the start of an operant experiment-on human fixed-interval performance were investigated in a between-groups design. Each of four groups of subjects was exposed to only one set of the following instructions: (1) instructions that described the apparatus but not the response manipulandum; (2) same as Instruction 1, but with a description of the response manipulandum; (3) same as Instruction 2, but with a demonstration of the response; or (4) same as Instruction 3, but with an additional instruction to maximize reinforcement. Each of the instructional sets differentially affected responding between groups: Instruction 1 produced the lowest rates and Instruction 4 produced the highest. Thus, different orienting instructions, as discriminative stimuli, do not set equivalent occasions for responding. Moreover, orienting instructions may interact with scheduled contingencies and/or contingency-specifying instructions to jointly control human performance in operant contexts.
\end{abstract}

The use of instructions is a prominent methodological feature of the experimental analysis of human behavior. Operant researchers interested in the effects of instructions on human behavior have typically examined functional relations between verbal instructions regarding scheduled contingencies and the pattern and rate of behavior emitted (for a review, see Baron \& Galizio, 1983). For example, when given erroneous instructions about simple schedules of reinforcement, subjects were more likely to respond in a pattern conforming to the instructed contingency rather than the scheduled contingency (e.g., Kaufman, Baron, \& Kopp, 1966; Lippman \& Meyer, 1967). Other instructional arrangements have produced strong control over responding on more complex schedules (e.g., Galizio, 1979; Harzem, Lowe, \& Bagshaw, 1978).

Whether or not human operant researchers are interested in the relation between contingency-specifying instructions and responding, it is characteristic of all human operant research that subjects receive instructions regarding the experimental apparatus, task, and contextual stimuli. These "orienting instructions" vary in kind and degree beyond mere description of the response involved. Some researchers have described to their subjects relevant contextual stimuli and the type of response to be emitted (e.g., Catania, Matthews, \& Shimoff, 1982). Shimoff, Catania, and Matthews (1981) instructed subjects to respond slowly while performing on a DRL schedule. Duvinsky and Poppen (1982), Poppen (1982), and

Reprint requests may be addressed to D. J. Terrell, Psychology Department, Auburn University, AL 36849-3501.
Stromer and Osborne (1982) demonstrated the response to be made. Other investigators have instructed their subjects to maximize reinforcement ("the task is to earn as many points as possible," e.g., Harzem et al., 1978; Shimoff et al., 1981). Still other researchers have explicitly stated the experimental task (e.g., Perone \& Baron, 1980; Poppen, 1982). Unfortunately, the control which such orienting instructions might exert over human behavior in operant contexts has not been studied systematically. In the present study, we manipulated some of the more obvious components of orienting instructions, including a description of the response manipulandum, a demonstration of the appropriate response (i.e., leverpressing), and a command to maximize obtained reinforcement. In order to replicate the traditional use of orienting instructions (subjects usually receive only one set of orienting instructions during any experiment), a between-group design was employed in which each group received only one set of orienting instructions.

\section{METHOD}

\section{Subjects}

Twenty-four Auburn University students (11 males and 13 females) volunteered. Subjects received introductory psychology class credit in exchange for participation. All subjects reported no experience with behavioral research.

\begin{abstract}
Apparatus
Subjects were seated before either of two identical six-panel response consoles which were housed in identical sound-attenuated and darkened cubicles (122-cm square). The console measured $65.5 \times 59.5 \times 36 \mathrm{~cm}$ and sat on a 70-cm-high table. The front portion of the console slanted upward at an angle of $25^{\circ}$. A 4-unit LED counter was mounted on the lower center panel at a height of $18 \mathrm{~cm}$. Directly above the center of the counter, at distances of 2.5 and $15.5 \mathrm{~cm}$, respectively, were two lights: an amber run light and a green reinforcement-feedback light. In
\end{abstract}


front of the console was a small metal box $(10 \times 10.5 \mathrm{~cm})$ which contained a standard Gerbrands primate lever.

All experimental conditions and data collection were controlled by a TRS- 80 Model 1 microcomputer located in a room adjacent to the cubicles.

\section{Procedure}

Subjects were randomly divided into four groups of 6 subjects each. Prior to the initial 12-min session, each subject was read the following (OPERANT LEVEL) instructions: "Please remain in this booth until I return for you. You may do anything you wish but please stay in the booth." During the first session, the amber light was illuminated for $12 \mathrm{~min}$ and leverpresses were recorded. Responses during this session had no programmed consequences.

Prior to the second session, each subject was read only one of four sets of orienting instructions. Group designations and instructions were as follows: (1) Orienting instructions omitting lever description (NO LEV DES).

The amber light is a signal that indicates that the experimental session has started; when it goes off permanently, the session is over. Every time you receive points on the counter, the amber light will go off for a few seconds and the green light will come on. Each illumination of the green light will indicate that you have earned 25 points. These points will be added to any points which you may have already earned.

(2) Regular orienting instructions omitting the response demonstration (REG-NO DEMO). These subjects received the same orienting instructions as did the NO LEV DES subjects with the exception that they were given an additional instruction regarding the lever prior to being read the instructions above:

By depressing this lever you may earn points on this counter. Every leverpress, however, may not result in accumulating points on the counter.
(3) Regular orienting instructions with a response demonstration (REG W/DEMO). These subjects received identical instructions as did the REG-NO DEMO subjects; however, when reference was made to the response lever, the experimenter demonstrated its operation by rapidly making five successive presses on the lever. (4) Regular orienting instructions with a statement to maximize point earnings in combination with demonstration (REG-DEMO-MAX). These subjects received identical instructions and demonstration as did the REG W/DEMO subjects, but with an added statement:

Your task is to earn as many points as possible. Let me repeat, earn as many points as possible.

Any questions by the subjects were answered by rereading the appropriate portion of the instructions or by stating that the question could not be answered at that time. A typed set of the appropriate instructions was left with subjects during all experimental sessions. During the next 10 sessions (each lasting $12 \mathrm{~min}$ ), leverpresses produced 25 points and a 2.5-sec illumination of the green light according to an FI 30-sec schedule. At the end of the experiment, each subject was interviewed and debriefed.

\section{RESULTS AND DISCUSSION}

Response rates (responses per minute) are depicted for each subject in each group in Figure 1. Few or no responses were emitted by subjects in all groups during the OPERANT LEVEL (OL) session, indicating that without orienting instructions about the experimental situation, little responding occurred. Response rates for all subjects in the NO LEV DES group remained very low

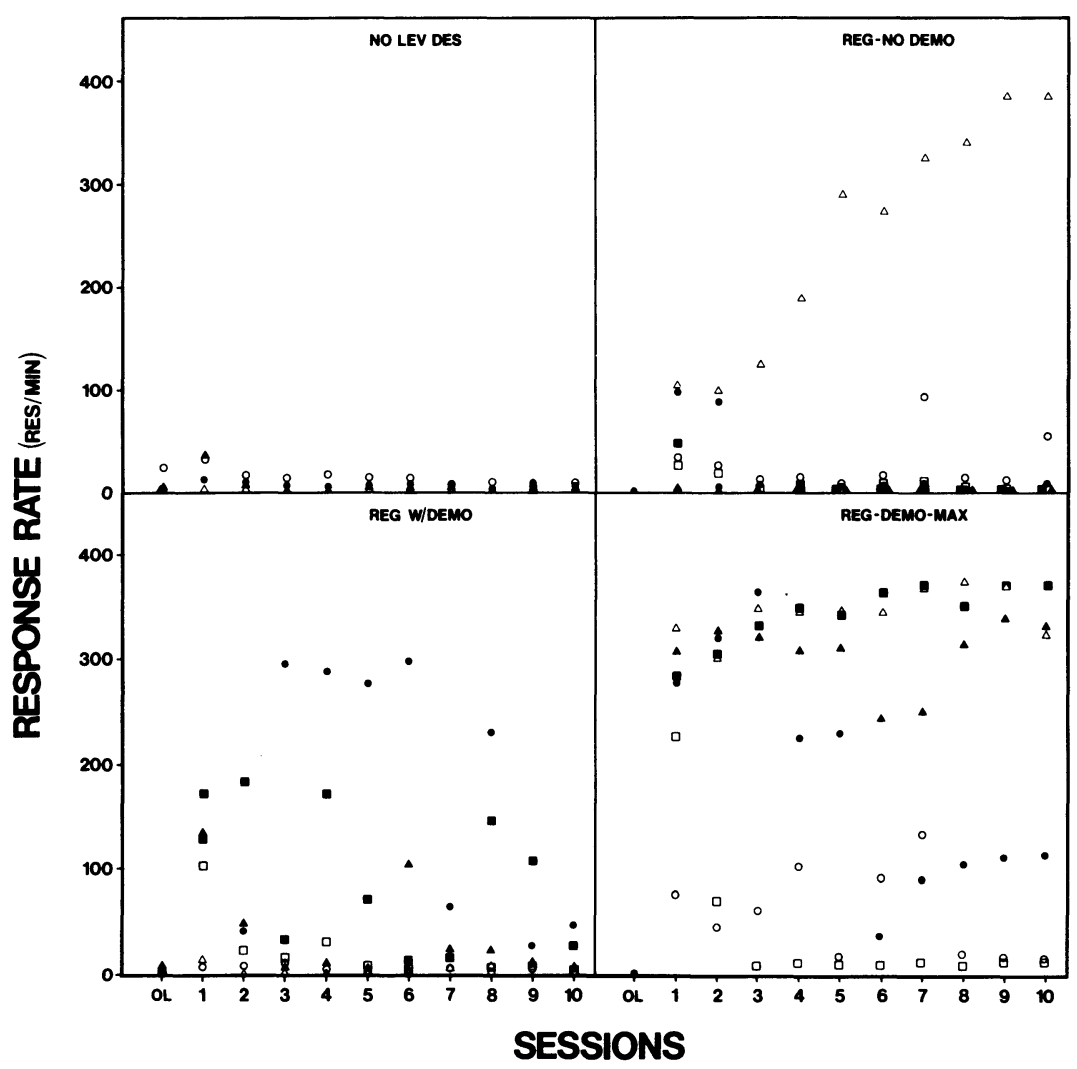

Figure 1. Response rates (responses per minute) for each session for subjects in each group of Experiment 1. Different symbols within each quadrant represent different subjects in that group. The OL session is the OPERANT LEVEL (uninstructed) session. Numbered sessions followed the presentation of instructions. 
and stable across all sessions. In comparison, response rates for subjects in the REG-NO DEMO group were slightly higher during the first instructional session but, with the exception of one subject (open triangles), rates decreased over subsequent sessions. In general, response rates for subjects in the REG-NO DEMO group (all but open triangles) resembled those of the NO LEV DES subjects. Subjects given instructions that included a response demonstration responded at a higher rate than did each NO LEV DES subject and most of the REG-NO DEMO subjects. Intersubject variability across sessions for REG W/DEMO subjects was also greater than that for NO LEV DES and REG-NO DEMO subjects. In spite of the high initial response rates, all subjects in this group decreased responding considerably by Session 10 . Subjects instructed to maximize point earnings (REG-DEMO-MAX) emitted the highest response rates throughout the experiment. Four of these subjects responded at rates over 100 responses per minute.

The median response rates (responses per minute) for the first instructional session for each group were: NO LEV DES, 9.31; REG-NO DEMO, 42.35; REG W/DEMO, 119.08; REG-DEMO-MAX, 281.38. Median response rates for the last session for each group were: NO LEV DES, 4.52; REG-NO DEMO, 6.37; REG W/DEMO, 3.45; REG-DEMO-MAX, 245.34, indicating that with continued exposure to scheduled contingencies, overall response rates for each group decreased. Kruskal-Wallis analyses indicated that there were significant group differences between response rates in both the first $[H(3)=7.89, p<.05]$ and last $[H(3)=10.50$, $p<.02$ ] sessions. Post hoc multiple comparisons indicated that reliable differences in first session response rates were between the NO LEV DES and REG-DEMO-MAX groups $(p<.05)$. The differences in last session response rates were between group REG-DEMO-MAX and all other groups (for each, $p<.05$ ).

The four types of orienting instructions produced different response rates under indentical programmed reinforcement contingencies with NO LEV DES instructions producing the lowest response rates and REG-DEMOMAX instructions producing the highest. Little intersubject variability characterized the performance of group NO LEV DES, and group REG-DEMO-MAX showed the largest level of variability. Except for 2 subjects, instructions which included a description of the lever but omitted a demonstration of the response (REG-NO DEMO) did not engender responding over the rate produced when the lever description was omitted (cf. NO LEV DES and REG-NO DEMO groups, Figure 1). Subjects given a response demonstration responded similarly to those not given a demonstration (cf. REG-NO DEMO and REG W/DEMO).
Taken together, these data illustrate a critical point regarding the relationship between orienting instructions and the initial responding of humans in an experimental situation. The nature of specific orienting instructions clearly affects subjects' responding; that is, different orienting instructions do not each set the same occasion for response acquisition. Such a finding is important in light of the fact that there seem to be so many different ways to acquaint humans with the apparatuses and response manipulanda used in different operant contexts, and the results suggest that human operant researchers may use different orienting instructions, particularly NO LEV DES and REG-DEMO-MAX instructions, to engender desired levels of responding in their subjects. More importantly, it is likely that human performance in most operant contexts is a function of the particular blend of orienting instructions, scheduled contingencies, and other instructions which specify response-reinforcer relations concocted by the researcher(s) involved. In such cases, the interaction of orienting instructions with these other variables may obscure the determinants of the behavior under investigation.

\section{REFERENCES}

BARON, A., \& GALIzIo, M. (1983). Instructional control of human operant behavior. The Psychological Record, 33, 495-520.

Catania, A. C., Matthews, B. A., \& Shimoff, E. (1982). Instructed versus shaped human verbal behavior: Interactions with nonverbal responding. Journal of the Experimental Analysis of Behavior, 38, 233-248.

Duvinsky, J. D., \& PopPen, R. (1982). Human performance on conjunctive fixed-interval fixed-ratio schedules. Journal of the Experimental Analysis of Behavior, 37, 243-250.

GaLIZIO, M. (1979). Contingency-shaped and rule-governed behavior: Instructional control of human loss avoidance. Journal of the Experimental Analysis of Behavior, 31, 53-70.

Harzem, P., Lowe, C. F., \& Bagshaw, M. (1978). Verbal control in human operant behavior. The Psychological Record, 28, 405-423.

Kaufman, A., Baron, A., \& Kopp, R. E. (1966). Some effects of instructions on human operant behavior. Psychonomic Monograph Supplements, 11, 343-350.

LipPMAN, G., \& MEYER, M. E. (1967). Fixed-interval performance as related to instructions and to subjects' verbalizations of the contingency. Psychonomic Science, 8, 135-136.

Perone, M., \& Baron, A. (1980). Reinforcement of human observing behavior by a stimulus correlated with extinction or increased effort. Journal of the Experimental Analysis of Behavior, 34, 239-261.

PopPEN, R. (1982). Human fixed-interval performance with concurrently programmed schedules: A parametric analysis. Journal of the Experimental Analysis of Behavior, 37, 251-266.

Shimoff, E., Catania, A. C., \& Matthews, B. A. (1981). Uninstructed human responding: Sensitivity of low-rate performance to schedule contingencies. Journal of the Experimental Analysis of Behavior, 36, 207-220.

Stromer, R., \& Osborne, J. G. (1982). Control of adolescents' arbitrary matching-to-sample by positive and negative stimulus relations. Journal of the Experimental Analysis of Behavior, 37, 329-348.

(Manuscript received for publication October 21, 1985.) 